\title{
Применение методов радиоспектроскопии для исследования термоэлектриков со структурой халькопирита
}

\author{
(C) В.Л. Матухин ${ }^{1}$, А.Н. Гавриленко ${ }^{1, \uparrow, ~ Е . В . ~ Ш м и д т ~}{ }^{1}$, С.Б. Орлинский ${ }^{2}$, И.Г. Севастьянов ${ }^{1}$, \\ C.O. Гарькавый ${ }^{1}$, J. Navratil ${ }^{3}$, P. Novak ${ }^{3}$ \\ ${ }^{1}$ Казанский государственный энергетический университет, \\ 420066 Казань, Россия \\ ${ }^{2}$ Казанский федеральный университет, \\ 420008 Казань, Россия \\ ${ }^{3}$ Institute of Physics of the Czech Academy of Sciences, \\ 16200 Praha 6, Czech Republic \\ ฯ E-mail: ang_2000@mail.ru \\ Поступила в Редакцию 19 сентября 2021 г. \\ В окончательной редакции 24 сентября 2021 г. \\ Принята к публикации 24 сентября 2021 г.
}

Рассмотрены легированные соединения халькопирита. Приведены результаты изучения спектральных параметров методом ядерного магнитного резонанса ${ }^{63,65} \mathrm{Cu}$ в локальном поле, а также методом электронного парамагнитного резонанса в интервале температур 15-300 К. Наблюдаемое уширение резонансных линий спектров ядерного магнитного резонанса и обнаружение парамагнитного сигнала в образце при температуре $15 \mathrm{~K}$ свидетельствуют о появлении антиструктурных дефектов. Быстрое изменение формы линии спектра электронного парамагнитного резонанса в интервале температур 100-130 К связывается со структурнофазовым переходом.

Ключевые слова: термоэлектрики, соединения халькопирита, антиструктурные дефекты.

DOI: $10.21883 /$ FTP.2022.01.51807.23

\section{1. Введение}

Высокоэффективные термоэлектрические материалы привлекают большое внимание из-за их потенциального применения в получении энергии, особенно для вторичного использования тепла, которое является побочным результатом технологических процессов. Недавно было предложено использовать магнитные полупроводники в качестве эффективных термоэлектриков [1]. Одной из характерных особенностей магнитных полупроводников является сильная связь между носителями и спинами магнитных ионов. Это сильное взаимодействие может привести к большой эффективной массе носителей, которая может увеличить коэффициент Зеебека при хорошей проводимости носителей. Одним из представителей этого класса соединений является широко известный полупроводниковый минерал халькопирит $\mathrm{CuFeS}_{2}$.

Недавние исследования показали возможное улучшение термоэлектрических свойств этого соединения, особенно за счет разбавленного легирования [2,3]. Для получения высокоэффективных термоэлектрических соединений необходимо детальное понимание изменений структурных характеристик и происходящих при легировании процессов.

В данной работе представлено исследование серии соединений $\mathrm{Cu}_{1-x} \mathrm{Pd}_{x} \mathrm{FeS}_{2}(x=0-0.02)$ методами ядерного магнитного резонанса (ЯМР) ${ }^{63,65} \mathrm{Cu}$ в локальном поле и электронного парамагнитного резонанса (ЭПР). Ранее были изучены термоэлектрические и транспорт- ные свойства образцов $\mathrm{Cu}_{1-x} \mathrm{Pd}_{x} \mathrm{FeS}_{2}(x=0-0.1)$ в виде горячепрессованных таблеток [4].

\section{2. Эксперимент}

Поликристаллические образцы с номинальным составом $\mathrm{Cu}_{1-x} \mathrm{Pd}_{x} \mathrm{FeS}_{2}(x=0,0.01,0.02)$ были синтезированы из смеси чистых элементов, полученных от SigmaAldrich, включая $\mathrm{Cu}$ (4N порций), $\mathrm{Pd}$ ( $4 N$ порошок), $\mathrm{Fe}$ (4N гранулированный) и $\mathrm{S}$ (5 порошок). Синтез образцов описан в работе [4].

Спектральные параметры ЯМР ${ }^{63,65} \mathrm{Cu}$ в локальном поле в $\mathrm{CuFeS}_{2}$ были измерены на многоимпульсном ЯКР/ЯМР-спектрометре Tecmag Redstone. Измерение формы линии ЯМР проводили с помощью квадратурного детектирования путем регистрации сигналов спинового эха с пошаговым прохождением частотного диапазона и накоплением сигнала.

Спектры ЭПР трех образцов $\mathrm{Cu}_{1-x} \mathrm{Pd}_{x} \mathrm{FeS}_{2} \quad(x=0$, $0.01,0.02)$ были исследованы на стационарном рентгеновском спектрометре ESP-300 в интервале температур 15-300 К. Массы образцов были примерно одинаковы и составляли $\sim 20$ мг.

\section{3. Результаты и обсуждение}

Детальное изучение формы резонансных линий показало их асимметричный характер с более пологим затуханием в высокочастотной области. 
Экспериментальный спектр ЯМР Сu соединений при $77 \mathrm{~K}$ можно рассматривать как суперпозицию двух спектров ЯМР Сu: первый спектр, состоящий из низкочастотных резонансных линий, отнесенных к основной фазе (синие линии $l_{1}, l_{1}^{\prime}, c_{1}, c_{1}^{\prime}, h_{1}, h_{1}^{\prime}$ на рис. 1$)$, и второй спектр, состоящий из высокочастотных линий, обусловленных резонансными центрами, расположенными в дефектных областях кристаллической структуры (красные линии $l_{2}, l_{2}^{\prime}, c_{2}, c_{2}^{\prime}, h_{2}, h_{2}^{\prime}$ на рис. 1).

Уширение резонансных линий может быть результатом увеличения количества дефектов в кристаллической решетке соединения, что приводит к большему разбросу градиента электрического поля (ГЭП) на резонансных ядрах меди. Образование таких дефектов $\left(\mathrm{Fe}_{\mathrm{Cu}}^{2+}\right.$ антиструктурные (AS) дефекты, как предложено в работе [4]) вызвано образованием фазы PdS в матрице халькопирита с увеличением номинального содержания Pd. Частотный сдвиг резонансных линий можно объяснить взаимодействием Рудермана-Киттеля-Касуя-Йосиды (РККИ) [5]. Об этом свидетельствует повышенная проводимость образца $\mathrm{Cu}_{0.98} \mathrm{Pd}_{0.02} \mathrm{FeS}_{2}$ [4].

Спектры ЭПР всех образцов имеют свои особенности. Значительный сдвиг центра линии вправо и его сужение

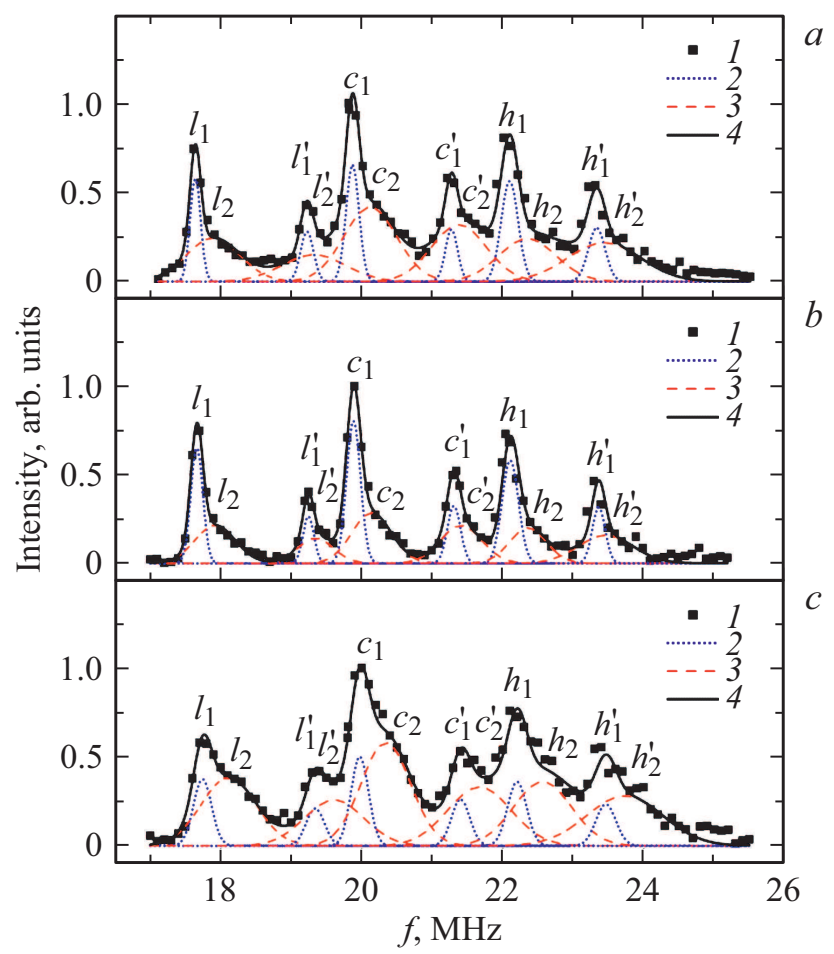

Pис. 1. ЯМР спектры ${ }^{63,65} \mathrm{Cu}$ в локальном поле при температуре $77 \mathrm{~K}$ образцов $\mathrm{CuFeS}_{2}(a), \mathrm{Cu}_{0.99} \mathrm{Pd}_{0.01} \mathrm{FeS}_{2}$ (b) и $\mathrm{Cu}_{0.98} \mathrm{Pd}_{0.02} \mathrm{FeS}_{2}$ (c). 1 - экспериментальные данные, 2 узкая линия $\left(l_{1}, l_{1}^{\prime}, c_{1}, c_{1}^{\prime}, h_{1}, h_{1}^{\prime}\right), 3$ - широкая линия $\left(l_{2}, l_{2}^{\prime}, c_{2}\right.$, $\left.c_{2}^{\prime}, h_{2}, h_{2}^{\prime}\right), 4$ - линия накопления. На рисунке представлены пунктирная (2) и штриховая (3) кривые, указывающие на расщепление каждой резонансной линии (1 или 4) на две пары линий.

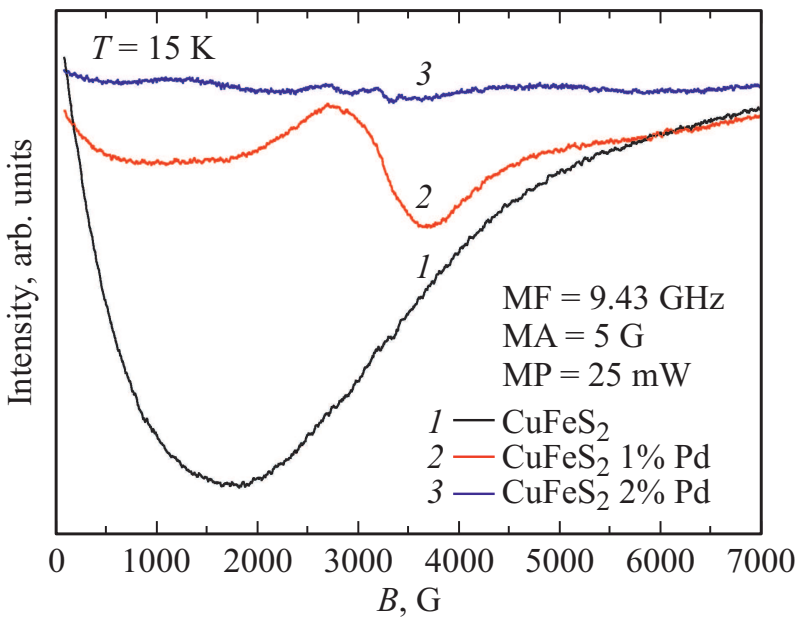

Рис. 2. Спектры ЭПР при температуре $15 \mathrm{~K}$ образцов $\mathrm{CuFeS}_{2}(1), \mathrm{Cu}_{0.99} \mathrm{Pd}_{0.01} \mathrm{FeS}_{2}$ (2) и $\mathrm{Cu}_{0.98} \mathrm{Pd}_{0.02} \mathrm{FeS}_{2}$ (3).

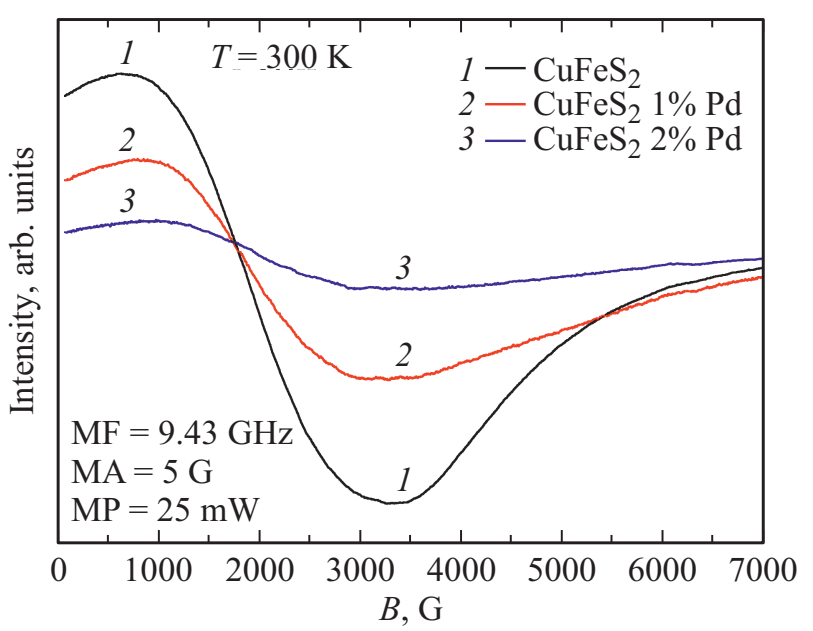

Рис. 3. Спектры ЭПР при температуре $300 \mathrm{~K}$ образцов $\mathrm{CuFeS}_{2}$ (1), $\mathrm{Cu}_{0.99} \mathrm{Pd}_{0.01} \mathrm{FeS}_{2}$ (2) и $\mathrm{Cu}_{0.98} \mathrm{Pd}_{0.02} \mathrm{FeS}_{2}$ (3).

в образце $\mathrm{CuFeS}_{2}(0 \% \mathrm{Pd})$ происходит в интервале температур $100-130 \mathrm{~K}$.

При низкой температуре $T=15 \mathrm{~K}$, в отличие от предыдущего образца без $\mathrm{Pd}$ в в образце с содержанием $\mathrm{Pd}$, равным $1 \%$, практически отсутствует часть широкого ферромагнитного сигнала; однако наблюдается, предположительно, парамагнитный сигнал с $g$-фактором, равным 2.08, и шириной $\sim 1$ кГц (рис. 2), который постепенно ослабевает и сужается с ростом температуры. В образце с содержанием $\mathrm{Pd}$, равным $2 \%$, сигнал около $g=2.00$ имеет меньшую интенсивность (рис. 2). Он повторяет поведение сигнала в образце с содержанием $\mathrm{Pd}$, равным $1 \%$, при нагревании.

При температуре $150 \mathrm{~K}$ и выше характер температурной зависимости одинаков для всех образцов. Форма линий всех образцов одинакова и в этом интервале температур, хотя есть разница в интенсивностях. Спектры ЭПР образцов при $300 \mathrm{~K}$ представлены на рис. 3. 


\section{4. Заключение}

Уширение резонансных линий ЯМР может быть результатом увеличения количества дефектов в кристаллической решетке соединения, что приводит к большему разбросу ГЭП на резонансных ядрах меди. Такими дефектами могут быть дефекты антиструктуры $\mathrm{Fe}_{\mathrm{Cu}}^{2+}(\mathrm{AS})$. Образование таких дефектов обусловлено образованием фазы PdS в матрице халькопирита с увеличением номинального содержания Pd. Таким образом, показано, что метод ЯМР $\mathrm{Cu}$ в локальном поле может быть использован для оценки дефектности поликристаллических соединений $\mathrm{Cu}_{1-x} \mathrm{Pd}_{x} \mathrm{FeS}_{2}(x=0-0.02)$.

Обнаружено быстрое изменение формы спектра ЭПР в интервале температур 100-130К в образце $\mathrm{CuFeS}_{2}$, что, предположительно, соответствует возможному структурному фазовому переходу.

В спектрах ЭПР образца $\mathrm{CuFeS}_{2}: \mathrm{Pd} 1 \%$ при температуре $T=15 \mathrm{~K}$ наблюдается парамагнитный сигнал с $g$-фактором, равным 2.08, и шириной $\sim 1$ кГц, что может быть связано с появлением антиструктурных дефектов.

\section{Благодарности}

Авторы благодарят Чешский научный фонд за финансовую поддержку, проект № 18-12761S.

\section{Конфликт интересов}

Авторы заявляют, что у них нет конфликта интересов.

\section{Список литературы}

[1] N. Tsujii. J. Electron. Mater., 42, 1974 (2013).

[2] H. Takaki, K. Kobayashi, M. Shimono, N. Kobayashi, K. Hirose, N. Tsujii, T. Mori. Mater. Today Phys., 3, 85 (2017).

[3] H. Takaki, K. Kobayashi, M. Shimono, N. Kobayashi, K. Hirose, N. Tsujii, T. Mori. Appl. Phys. Lett., 110, 072107 (2017).

[4] J. Navratil, J. Kasparova, T. Plechacek, L. Benes, Z. OlmrovaZmrhalova, V. Kucek, C. Drasar. J. Electron. Mater., 48, 1795 (2019).

[5] T. Koyama, M. Matsumoto, S. Wada, Y. Muro, M. Ishikawa. J. Phys. Soc. Jpn., 70, 3667 (2001).

Редактор А.Н. Смирнов

\section{Application of radio spectroscopy methods for the study of thermoelectrics with a chalcopyrite structure}

\author{
V.L. Matukhin ${ }^{1}$, A.N. Gavrilenko' ${ }^{1}$, E.V. Schmidt ${ }^{1}$, \\ S.B. Orlinskii ${ }^{2}$, I.G. Sevastianov ${ }^{\mathbf{1}}$, S.O. Garkavyi ${ }^{\mathbf{1}}$, \\ J. Navratil ${ }^{3}$, P. Novak ${ }^{3}$ \\ ${ }^{1}$ Kazan State Power Engineering University, \\ 420066 Kazan, Russia \\ 2 Kazan Federal University, \\ 420008 Kazan, Russia \\ ${ }^{3}$ Institute of Physics of the Czech Academy \\ of Sciences, \\ 16200 Praha 6, Czech Republic
}

Abstract Doped chalcopyrite compounds are considered. The results of studying the spectral parameters by the ${ }^{63,65} \mathrm{Cu}$ NMR method in a local field, as well as by the EPR method in the temperature range $15-300 \mathrm{~K}$ are presented. The observed broadening of the resonance lines of the NMR spectra and the detection of a paramagnetic signal in the sample at a temperature of $15 \mathrm{~K}$ indicate the appearance of anti-structural defects. The rapid change in the shape of the EPR spectrum line, in the temperature range $100-130 \mathrm{~K}$, is associated with the structuralphase transition. 